\title{
Residual debris as a potential cause of postphaco- emulsification endophthalmitis
}

\begin{abstract}
Aim To examine residual debris within sterilised instruments prior to cataract surgery. Methods

(i) Flushings from 32 sets of phacoemulsification instruments, sterilised according to hospital routine protocols, were taken preoperatively and analysed by scanning electron microscopy (SEM).
\end{abstract}

(ii) A total of $\mathbf{1 6}$ sets of flushings from a different institute were collected - with separation of samples collected from phacoemulsification and those from irrigation-aspiration (IA) instruments - and analysed in the same way.

(iii) A total of 15 sets of flushings were collected from instruments where an

Tennent Institute of Ophthalmology Gartnavel General Hospital Glasgow UK

Correspondence: T Leslie, c/o Tennent Institute, Gartnavel General Hospital, 1053 Great Western Road, Glasgow G12 OYN, UK

Tel: +441412111041

Fax: + 441412112054

E-mail: thorfinnleslie@

hotmail.com

Received: 19 February 2002 Accepted in revised form: 7 October 2002

Presented as a free paper at the Royal College of Ophthalmologists Annual Congress, 24 Birmingham, May 2001

Financial/proprietary interests: None automated flushing system was used prior to sterilisation.

Results

(i) In the first study, $62 \%$ were clean, $16 \%$ were moderately contaminated and $22 \%$ were severely contaminated. Various contaminants were identified including lens capsule and cells, man-made fibres, squamous cells, bacteria, fungal elements, diatoms, red blood cells and proteinaceous material.

(ii) In the second study, the results were similar and contamination of both phacoemulsification and IA instruments was shown.

(iii) The third study showed that although a decrease in contamination followed automated flushing, contamination was not completely eliminated.

Conclusions Although all equipment had been sterilised, pyrogenic material was still present. These findings emphasise the importance of meticulous cleaning of all surgical equipment in which biological debris can remain.
T Leslie, DA Aitken, T Barrie and CM Kirkness

Eye (2003) 17, 506-512. doi:10.1038/

sj.eye. 6700404

Keywords: sterile; postoperative; endophthalmitis; electron microscopy; pyrogenic; phacoemulsification

\section{Introduction}

Endophthalmitis is potentially the most serious of the postoperative complications of phacoemulsification cataract surgery. Its incidence has been reported to be $0.07-0.12 \% .^{1-6}$ The Endophthalmitis Vitrectomy Study (EVS) found an overall culture-positivity rate of $69.3 \%$ with equivocal growth in $12.8 \%$ following aqueous and vitreous biopsy. ${ }^{7}$ These are usually adnexal commensals, namely coagulasenegative micrococci in $70 \%$ (mostly Staphylococcus epidermidis), Staphylococcus aureus in $10 \%$, Streptococcus species in $9 \%$,

Enterococcus in 2\%, other Gram positive species in $3 \%$ and other Gram negative species in $6 \%{ }^{7,8}$ The visual outcome is dependent on the visual acuity at initial presentation, the infecting organism and how quickly intravitreal antibiotic therapy is administered following onset. ${ }^{9}$ In the EVS, $53 \%$ had final visual acuities of $20 / 40$ or better and $11 \%$ had less than $5 / 200 .{ }^{10}$ Although cases of endophthalmitis are usually isolated, clustered outbreaks have been described and exogenous sources have sometimes been identified. ${ }^{11-25}$

In a 14-week period, at the end of 1999, there were eight cases of postphacoemulsification endophthalmitis in the Tennent Institute of Ophthalmology, Gartnavel General Hospital, Glasgow. The Tennent Institute is the tertiary referral unit for Glasgow and the West of Scotland. There are two dedicated eye theatres served by a general Theatre Sterilising Unit. At 
the time of the cluster, full hospital infection protocols were instituted - the Infection Control Team was contacted, theatres were closed for 2 weeks while individual cases were reviewed and sterilising procedures were examined. No single causative organism was found and cleaning/sterilising procedures were confirmed as being carried out according to the instrument distributor's and Medical Devices Agency's (MDA) recommendations. ${ }^{26}$ The Infection Control Team concluded that no specific cause could be identified.

We had also observed occasionally that aspiration was initially poor with the irrigation-aspiration (IA) handpiece. It seemed however to resolve following flushing of the handpiece. It was therefore postulated that the lumen may have been occluded with debris and further, that the contaminant might have had a role in postoperative inflammation - a hypothesis which was strengthened by the observation that the endophthalmitis patients appeared to respond to treatment unusually well. For this reason, it was decided to carry out a study looking at flushings from sterilised IA and phacoemulsification handpieces immediately preoperatively.

\section{Methods}

There were three separate studies that involved flushings collected from a total of 61 instrument sets immediately preoperatively from $13 / 12 / 99$ to $14 / 02 / 01$.

(i) The first study consisted of 32 sets of flushings from Gartnavel General Hospital.

(ii) The second study consisted of 16 sets of flushings from another hospital in Glasgow, where the flushings from the phacoemulsification and IA instruments were analysed separately.

(iii) The third study consisted of 15 sets of flushings collected from instruments where an automated flushing system was used prior to sterilisation.

'Controls' were also analysed-distilled water, glutaraldehyde, the buffers and flushings from all containers. All scanning electron microscopy (SEM) work, analysis and classification were carried out by one electron microscopist experienced in ocular pathology. The SEM was carried out using a proven method devised in our laboratory.

After the trolley was laid out, the scrub-nurse flushed the phacoemulsification handset and then the IA handset with each tip (straight, $45^{\circ}$ and $90^{\circ}$ ) in position - each time with approximately $5 \mathrm{ml}$ of distilled sterile water from a syringe. Each flushing was placed directly into a sterile container with approximately $10 \mathrm{ml}$ of $3 \%$ glutaraldehyde fixative. The specimens were centrifuged at $3000 \mathrm{rpm}$ for $15 \mathrm{~min}$ at each stage of the following processing and the resulting supernatant was carefully removed using a pastette and discarded:

1. Rinsed with cacodylate buffer four times.

2. Postfixed in osmium tetroxide.

3. Rinsed with cacodylate buffer four times.

4. Dehydrated in $25 \%$ alcohol.

5. Dehydrated in $50 \%$ alcohol.

6. Dehydrated in $75 \%$ alcohol.

7. Dehydrated in $100 \%$ alcohol four times.

A circle of aluminium foil was attached to a carbon sticky disc mounted on an aluminium SEM stub. The processed residue was agitated in the centrifuge tube and carefully dropped onto the foil using a fine-tipped pastette. The foil was covered and allowed to dry before being coated with gold by a Polaron SC 515 sputter coater. The foil was then examined in a JEOL 6400 scanning electron microscope (JEOL (UK) Ltd, JEOL House, Silver Court, Watchmead, Welwyn Garden City, Herts, UK). Each stub was surveyed at $\times 100$ magnification initially. Higher power views were employed where debris was found. The type of debris was categorised and the amount of each type was assessed and an arbitrary score from 0 to 4 was allocated for each category. The total score for each stub was then calculated by adding the scores for each type of debris per stub.

1. A score of 0-4 was designated 'clean.'

2. A score of 5-9 was designated 'moderately contaminated.'

3. A score of 10 or greater was designated 'severely contaminated.'

\section{Results}

In the first study of 32 instrument set flushings, where the flushings from each pair of instruments comprising a set were collected in one pot as one sample, $62 \%$ were designated as clean, $16 \%$ as moderately contaminated and $22 \%$ as severely contaminated. Regardless of amount, in 19 out of 32 flushings, lens capsule and cells were identified. Other contaminants identified included man-made fibres (18/ 32), squamous cells (18/32), bacteria (10/32) (using SEM, it is not possible to identify whether an organism is viable at the time of its retrieval), fungal elements (8/32), diatoms (6/32) (silica skeletons of unicellular plant organisms) and a mixture of red blood cells, proteinaceous material, and other unidentifiable material $(11 / 32)$. All controls were negative. See photomicrographs (Figures 1-7).

In the second study, 16 sets were collected from a different hospital in Glasgow and the flushings from the 


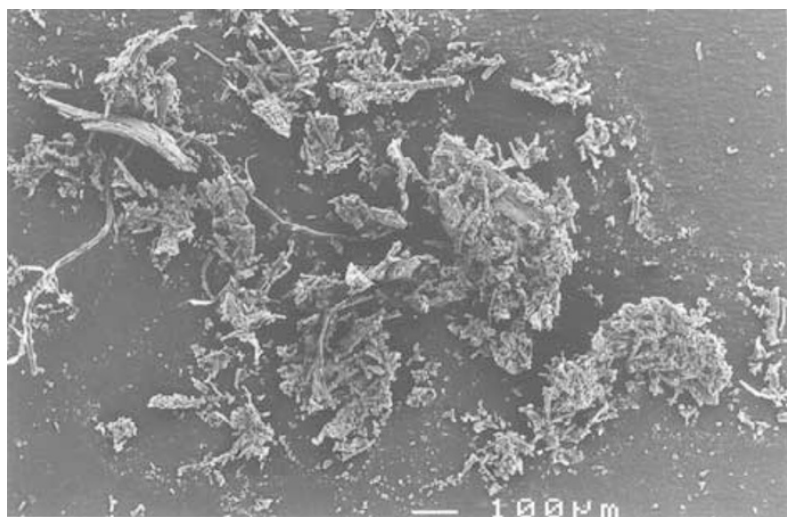

Figure 1 Low-power $(\times 60)$ view of debris (severe contamination).

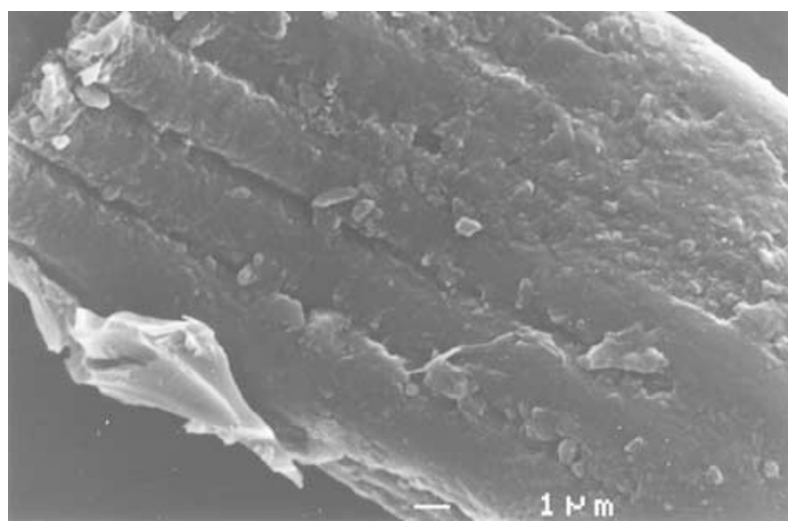

Figure 2 Lens fibres.

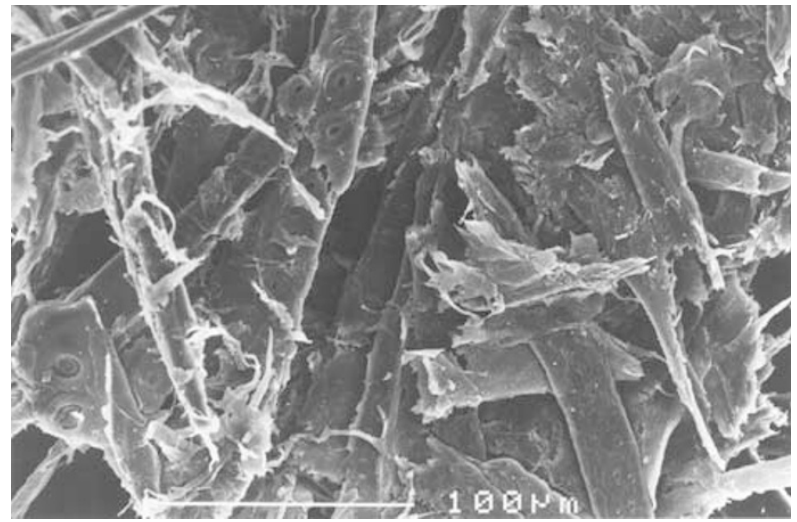

Figure 3 Natural fibres.

phacoemulsification and IA handsets were analysed separately. This study confirmed that both types of instrument showed contamination - the

phacoemulsification analysis showed $50 \%$ clean, $37.5 \%$

moderately contaminated and $12.5 \%$ severely contaminated; the IA analysis showed $68.75 \%$ clean, $25 \%$ moderately contaminated and $6.25 \%$ severely contaminated.

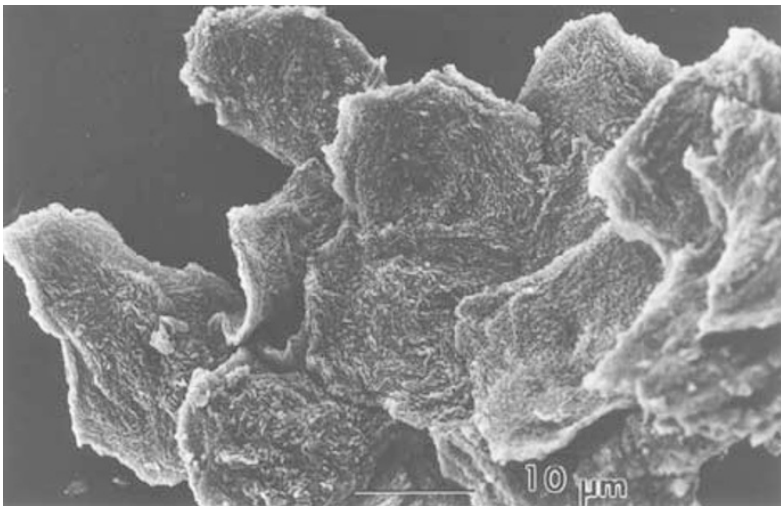

Figure 4 Squamous cells.

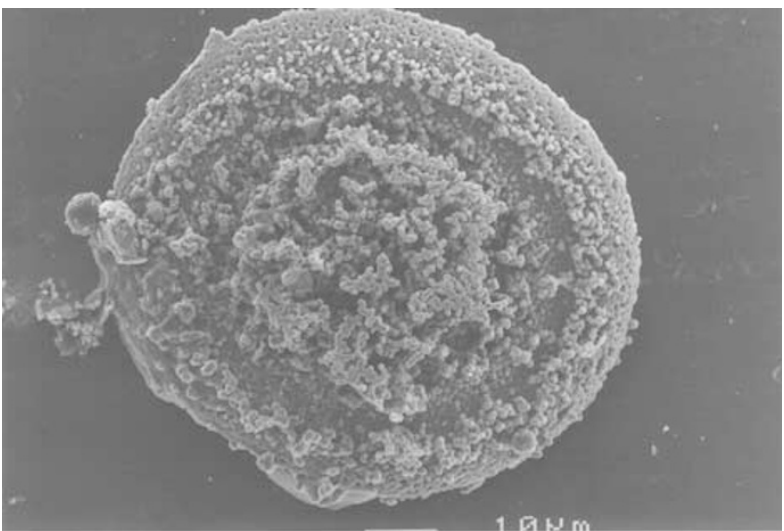

Figure 5 Bacterial colony.

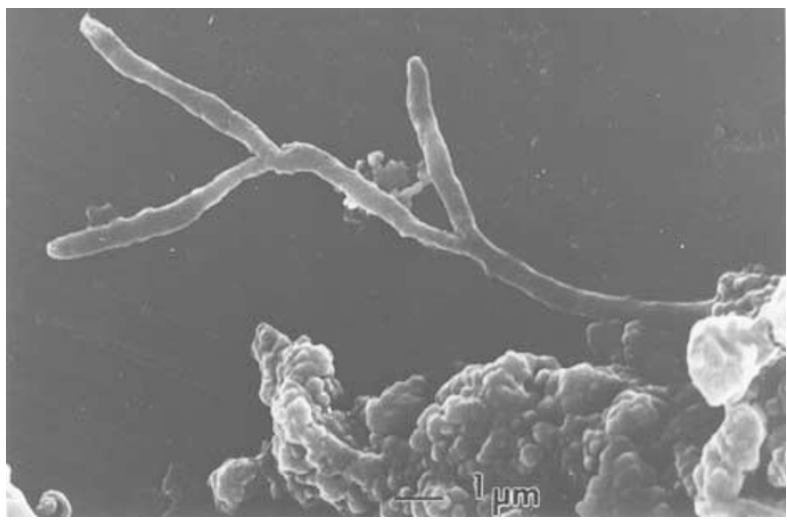

Figure 6 Fungal hyphae on degraded bacteria.

Following identification of contamination within the instruments, an IA handpiece and three tips (straight, $45^{\circ}$ and $90^{\circ}$ ) were sent to the manufacturer for analysis. All items were more than 2 years old - the $90^{\circ}$ tip was more than 4 years old. No corrosion of the internal surfaces of the handpiece was apparent. All three tips, however, showed signs of oxidation around the intersection of the aspiration and irrigation cannula. There was what 


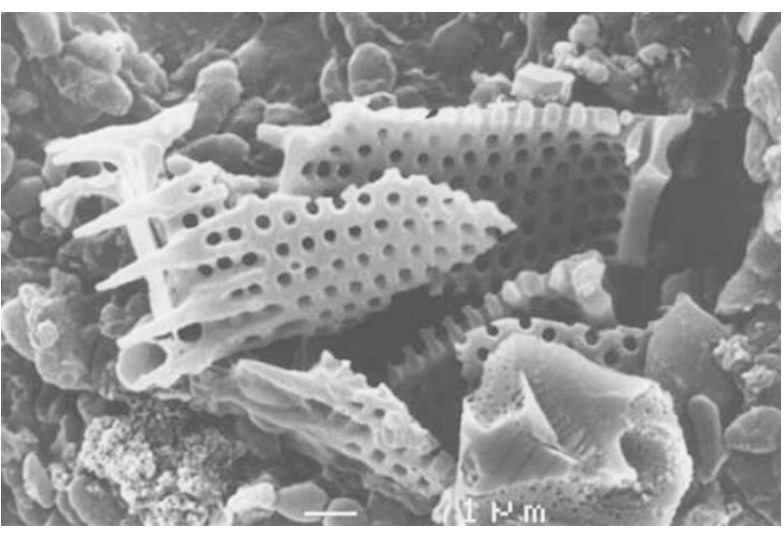

Figure 7 Diatoms.

appeared to be dried cortical lens material trapped in this area in keeping with our findings from the flushings. The manufacturer's report noted that microscopic evaluation 'revealed typical signs of field use and that the overall condition is typical of improperly(sic) maintained instruments.' The report concluded by recommending 'routine maintenance, cleaning with distilled water after each use and ultrasonic cleaning at least once per day.'

At the time in question the standard cleaning protocol for the instruments was that recommended by the instrument distributors - at the end of the operation the disposable phacoemulsification tip was discarded, the phacoemulsification handpiece was flushed with distilled water, and dried with injections of air from a syringe. The IA handpiece was flushed and dried in the same way with each interchangeable tip in position. The instruments were then packaged and sent to the general Theatre Sterilising Unit where they were autoclaved at $134^{\circ} \mathrm{C}$ for $3 \mathrm{~min}$ as recommended by the MDA. ${ }^{11}$ The distributors also recommended ultrasonic cleaning if there was suspicion of retained material on direct visualisation through the lumen or if the fluid jet appeared suspicious of obstruction on flushing the instrument.

To standardise the cleaning regime, an automated rinsing system - American Optisurgical Incorporated's Quickrinse Automated Instrument Rinse System - was purchased. This has a rinse cycle of $15 \mathrm{~s}$ of fluid (distilled water) followed by $15 \mathrm{~s}$ of air (under pressure of $30 \mathrm{psi}$ ) through the lumen of the instruments and tips. The instruments were then packaged and autoclaved as before.

The third part of the study analysed flushings from a further 15 sets (again combined), which were collected 3 months after the new rinsing system was introduced. The analysis was carried out by the same electron microscopist as in the original study. This further study showed $80 \%$ were clean, $13 \%$ showed moderate contamination and $7 \%$ severe contamination.
The endophthalmitis rate for 1999, the year of the endophthalmitis outbreak, was $0.91 \%$. The rate for the preceding year was lower at $0.16 \%\left(\chi^{2}\right.$ test $\left.P<0.05\right)$.

The new rinsing regime was introduced at the beginning of 2000. During 2000 there was one case of postphacoemulsification endophthalmitis giving a rate of $0.09 \%$, which is significantly less than the 1999 study period ( $\chi^{2}$ test $\left.P<0.005\right)$.

\section{Discussion}

Endophthalmitis is a relatively rare complication of phacoemulsification. A US Medicare survey in 1994 found an incidence of $0.08 \%$ and comparably the UK National Cataract Survey 1997/98 found a risk of 0.1\%.5 It has, however, been shown to occur more often in some studies - for example, as yet unpublished data from the British Ophthalmological Surveillance Unit's (BOSU) study of post cataract endophthalmitis October 1999September 2000 (personal communication) has indicated a rate approaching $0.2 \%$ and other studies have found higher incidences. ${ }^{27}$ In contrast, the cluster of eight cases occurring over a 14-week period at Gartnavel Hospital gave an overall incidence of $0.91 \%$ for 1999 .

In our study, four patients showed growth (a mixture of coagulase-negative Staphylococci, S. aureus and Streptococcus spp.), one was equivocal (culture negative but positive for bacteria on SEM) and three were negative. This represents a culture positivity rate of 50-62.5\%, lower than found in the Endophthalmitis Vitrectomy Study.

The visual outcome is dependent on the presenting visual acuity, the infecting organism and how quickly intravitreal antibiotic therapy is administered following onset. ${ }^{9}$ In the EVS study, $53 \%$ had final visual acuities of $20 / 40$ or better and $11 \%$ had less than $5 / 200 .{ }^{10}$ In our study, five patients achieved visual acuities of $6 / 12$ or better (62.5\%). Two patients were noted to have extensive ARMD preoperatively and achieved visual acuities of $6 / 18$ and $6 / 24$. One patient had a protracted infection with a visual outcome of $1 / 60$. These results are again better than in the Endophthalmitis Vitrectomy Study.

Most cases of endophthalmitis are isolated but clusters have been reported. Often no cause is found and sometimes no microorganism can be identified. ${ }^{9,11}$ Other outbreaks have been presumed to be because of defective sterilisation and/or poor operative room hygiene, ${ }^{12,13}$ and in these cases a variety of causative organisms can be found in one outbreak. In others, the same organism is implicated in all or most cases and intraoperative contamination can be identified, for example, internal contamination of the phacoemulsification machine ${ }^{14,15}$ or the vitrectomy apparatus; ${ }^{16,17}$ contamination of the ultrasonic cleaning bath and detergent, ${ }^{18}$ viscoelastic, ${ }^{19}$ 
balanced salt solution, ${ }^{20}$ ocular irrigation solution ${ }^{21,22}$ and lens implant neutralizing solution. ${ }^{23}$ The operating environment has also been identified as a potential source of infection, that is, contaminated humidifying water in the ventilation system ${ }^{24}$ or by construction work. ${ }^{25}$ The only previous study to examine postoperative phacoemulsification tip flushings for contamination looked for lens proteins using gel electrophoresis and Western blotting techniques, ${ }^{28}$ but it found that after regular cleaning of the phacoemulsification tips, no detectable lens proteins could be identified in the outflow samples.

We have shown the presence of microscopic debris within sterile instruments immediately preoperatively in two different ophthalmology units. Contemporary cleaning regimes were not completely effective at removing this debris. Fine wire brushes that are used in some units to clean the instrument lumens can themselves become contaminated with debris and microorganisms and can be detrimental to cleaning (personal observations). Automated flushing showed some improvement but contamination could still be identified in a significant proportion of the samples - this is not surprising as there is little actual difference between automated flushing and the standard method of flushing with syringes. In our parallel study, both IA and phacoemulsification handpieces showed evidence of contamination. It is possible that regular ultrasound cleaning of the IA handpieces could reduce the amount of contamination but the distributors of the phacoemulsification handpieces specifically warn against placing the phacoemulsification handpieces in ultrasound baths because of possible damage to the Piezo crystal.

It is unclear whether the contamination found in the handpieces is the cause of the cases of endophthalmitis seen in our unit. Similar contamination was found when the same investigations were carried out in another unit, but that unit had not experienced problems with endophthalmitis. As the phacoemulsification apparatus involved was of a common type and a standard cleaning regime was used, one could assume that if the same study were performed elsewhere, similar instrument contamination would be identified. It would seem likely that contamination is prevalent but it is possible that it only becomes clinically evident once a certain contamination load is reached. Other clusters of cases, although relatively rare in this country, have been noted (personal communication from BOSU and Allardice $e a^{29}$ ) but clusters are almost certainly under-reported, and if single cases of sterile endophthalmitis secondary to instrument contamination occurred, these would probably be assumed to be infective (but culture negative) with prompt response to treatment.

Confounding factors should also be taken into account. Although four of the eight patients had positive cultures and one was equivocal, it has been shown in several previous studies that 'false positives' can occur and that if noninfective control studies are carried out they also often show positives. ${ }^{30-32}$ It is therefore possible that some of the positive results are artefactual and that the endophthalmitis in these cases were not caused by the implicated organism. The use of the polymerase chain reaction for bacterial DNA in vitreous samples in future studies may decrease these artefacts.

Dinankaran and Kayarkar ${ }^{33}$ have pointed out that many surgical instruments may be contaminated with pyrogens presumably as residual detritus not removed after inadequate cleaning routines. These materials, which may be vegetable fibres, persisting soft lens matter or (degraded) dried viscoelastic have the potential to damage endothelium and produce sterile intraocular inflammation. ${ }^{34}$ Thus, there are a variety of routes by which potentially damaging material may be introduced into the eye by instruments that have passed through valid sterilising processes. It is furthermore possible that some organic debris may insulate bacteria from the sterilising process. ${ }^{35} \mathrm{It}$ is important that surgeons recognise the possibility that their instruments may be harbouring extraneous material that is potentially damaging. Hospital cleaning and sterilising procedures should take these risks, which may be unique to ophthalmology, into account when devising protocols. ${ }^{36}$ These risks have been highlighted by the Royal College of Ophthalmologists in a recent Focus publication. ${ }^{37}$

One limitation of this study is the lack of masking with the risk of introducing a potential source of bias. This could have been avoided if the person cleaning, flushing and sterilising the instruments was blinded to which instrument flushings were being analysed.

In conclusion, seven out of eight patients in our series had a better than expected clinical outcome with prompt resolution and good visual acuities. This along with our finding of residual biological debris within the instruments - of which the lens remnants must originate from previous surgical patients - prompts us to speculate whether pyrogenic material delivered from the instruments could have contributed a sterile element to the endophthalmitis in some of the cases. We feel that cataract surgeons should be aware of the possibility of retained biological debris, its possible role in sterile endophthalmitis and the necessity for meticulous cleaning, not just sterilization, of these instruments. 


\section{References}

1 Aaberg Jr TM, Flynn Jr HW, Schiffman J, Newton J. Nosocomial acute-onset postoperative endophthalmitis survey. Ophthalmology 1998; 105: 1004-1010.

2 Javitt JC, Vitale S, Canner JK, Street DA, Krakauer H, McBean AM et al. National outcomes of cataract extraction: endophthalmitis after inpatient surgery. Arch Ophthalmol 1991; 109: 1085-1089.

3 Kattan HM, Flynn Jr HW, Pfugfelder SC, Robertson C, Forster RK. Nosocomial endophthalmitis survey: current incidence of infection after intraocular surgery. Ophthalmology 1991; 98: 227-238.

4 Powe NR, Schein OD, Gieser SC, Tielsch JM, Luthra R, Javitt $\mathrm{J}$ et al (Cataract Patient Outcome Research Team). Synthesis of the literature on visual acuity and complications after cataract extraction with intraocular lens implantation. Arch Ophthalmol 1994; 112: 239-252.

5 Desai P, Minassian DC, Reidy A. National Cataract Survey 1997-98: a report of the results of the clinical outcomes. Br J Ophthalmol 1999; 83: 1336-1340.

6 Javitt JC, Street DA, Tielsch JM, Wang Q, Kolb MM, Schien $\mathrm{O}$ et al. (Cataract Patient Outcome Research Team). National outcomes of cataract surgery. Retinal detachment and endophthalmitis after outpatient cataract surgery. Ophthalmology 1994; 101: 100-105.

7 Han DP, Wisniewski SR, Wilson LA, Barza M, Vine AK, Doft $\mathrm{BH}$ et al. Spectrum and susceptibilities of microbiological isolates in the Endophthalmitis Vitrectomy Study. Am J Ophthalmol 1996; 122: 1-17.

8 Ormerod LD, Ho DD, Becker LE, Cruise RJ, Grohar HI, Paton BG et al. Endophthalmitis caused by the coagulasenegative staphylococci. Ophthalmology 1993; 100: 715-729.

9 Endophthalmitis Vitrectomy Study Group. The Endophthalmitis Vitrectomy Study: microbiological factors and visual outcome. Am J Ophthalmol 1996; 122: 830-846.

10 Endophthalmitis Vitrectomy Study Group. Results of the Endophthalmitis Vitrectomy Study: a randomised trial of immediate vitrectomy and of intravenous antibiotics for the treatment of postoperative bacterial endophthalmitis. Arch Ophthalmol 1995; 113: 1479-1496.

11 Nelson DB, Donnenfeld ED, Perry HD. Sterile endophthalmitis after sutureless cataract surgery. Ophthalmology 1993; 100: 441-442.

12 Pitaksiripan S, Butpongsapan S, Pravithayakarn L, Tippayadarapanich D. An outbreak of post-operative endophthalmitis in Lampang Hospital. J Med Assoc Thai 1995; 78(Suppl 2): S95-S98.

13 Swaddiwudhipong W, Linlawan P, Prasantong R, Kiphati R, Wongwatcharapaiboon P. A report of an outbreak of postoperative endophthalmitis. J Med Assoc Thai 2000; 83: 902-907.

14 Zaluski S, Clayman HM, Karsenti G, Bourzeix S, Tournemire A, Faliu B et al. Pseudomonas aeruginosa endophthalmitis caused by contamination of the internal fluid pathways of a phacoemulsifier. J Cataract Refract Surg 1999; 25: 540-545.

15 Mino de Kaspar, Grasbon T, Kampik A. Sterilization of phacoemulsification and vitrectomy instruments. Contamination and evaluation. Ophthalmologe 2000; 97: 703-707.

16 Kappstein I, Schneider CM, Grundmann H, Scholz R, Jnaknecht P. Long-lasting contamination of a vitrectomy apparatus with Serratia marcescens. Infect Control Hosp Epidemiol 1999; 20: 192-195.

17 Janknecht P, Kappstein I. Bacterial contamination of the pressure receiver of a vitrectomy machine. Ophthalmic Surg Lasers 1998; 29: 345-347.

18 Kreisler KR, Martin SS, Young CW, Anderson CW, Mamalis $\mathrm{N}$. Postoperative inflammation following cataract extraction caused by bacterial contamination of the cleaning bath detergent. J Cataract Refract Surg 1992; 18: 106-110.

19 Roy M, Chen JC, Miller M, Boyaner D, Kasner O, Edelstein E. Epidemic Bacillus endophthalmitis after cataract surgery I: acute presentation and outcome. Ophthalmology 1997; 104: 1768-1772.

20 Swaddiwudhipong W, Tangkitchot T, Silarung N An outbreak of Pseudomonas aeruginosa postoperative endophthalmitis caused by contaminated intraocular irrigating solution. Trans R Soc Trop Med Hyg 1995; 89: 288.

21 O'Day DM. Value of a centralized surveillance system during a national epidemic of endophthalmitis. Ophthalmology 1985; 92: 309-315.

22 Pettit TH, Olson RJ, Foos RY, Martin WJ. Fungal endophthalmitis following intraocular lens implantation. A surgical epidemic. Arch Ophthalmol 1980; 98: 1025-1039.

23 Arsan AK, Adisen A, Duman S, Aslan B, Kocak I. Acute endophthalmitis outbreak after cataract surgery. J Cataract Refract Surg 1996; 22: 1116-1120.

24 Fridkin SK, Kremer FB, Bland LA, Padhye A, McNeil MM, Jarvis WR. Acremonium kiliense endophthalmitis that occurred after cataract extraction in an ambulatory surgical center and was traced to an environmental reservoir. Clin Infect Dis 1996; 22: 222-227.

25 Tabbara KF, al Jabarti AL. Hospital construction-associated outbreak of ocular aspergillosis after cataract surgery. Ophthalmology 1998; 105: 522-526.

26 Medical Devices Agency Hazard Notice HN 9503, May 1995.

27 Strmen P, Hlavackova K, Ferkova S, Vavrova K Jakabovicova E, Vrastilova M. Endophthalmitis after intraocular interventions. Klin Monatsbl Augenheilkd 1997; 211(4): 245-249.

28 Nuyts RM, Van Boekel M, Bloemendal H, Hiddema F. Detection of lens proteins in phaco tips after phacoemusification. J Cataract Refract Surg 1999; 25: 1510-1514.

29 Allardice GM, Wright EM, Peterson M, Miller JM. A statistical approach to an outbreak of endophthalmitis following cataract surgery at a hospital in the West of Scotland. J Hosp Infect 2001; 49(1): 23-29.

30 Chern KC, Meisler DM, Hall GS, Meyers SM, Foster RE, Zakov $\mathrm{ZN}$ et al. Bacterial contamination of anaerobic vitreous cultures: using techniques employed for endophthalmitis. Curr Eye Res 1996; 15(6): 697-699.

31 Dhaliwal DK, Kowalski RP, Donahue SP, Doft BH, Karenchak LM. Evaluation of vitrectomy machines as a source of false-positive culture contamination in endophthalmitis. Am J Ophthalmol 1995; 119(1): 62-64.

32 Assalian A, Thompson P, St-Antoine P, Lemire J, Duperre J, Demers JP et al. Anterior chamber fluid contamination after uncomplicated phacoemulsification. J Cataract Refract Surg 1995; 21(5): 539-542.

33 Dinankaran S, Kayarkar VV. Debris on processed ophthalmic instruments: a cause for concern. Eye 2002; 16: 281-284. 
34 Sutphin JE, Papadimus TJ. Post-cataract extraction corneal oedema: epidemiological intervention and control. Invest Ophthalmol Vis Sci 1989; 30(Suppl): 165.

35 Miller $\mathrm{CH}$. Cleaning, sterilization and disinfection: basics of microbial killing for infection control. J Am Dent Assoc 1993; 124: 48-56.
36 Kirkness CM. Instrumental debris: Editorial. Eye (in press).

37 Ludgate S, Astbury N. Device related adverse events. Focus (Royal College of Ophthalmologists) 20: 2001. 